\title{
A Educação Especial no contexto italiano: o projeto de vida, da escola à vida adulta ${ }^{1}$
}

\author{
Melina Chassot Benincasa Meirelles* \\ Roberto Dainese* \\ Valeria Friso ${ }^{* * *}$
}

\section{Resumo}

O presente trabalho teve como objetivo analisar o conceito de projeto de vida no contexto italiano. Tal projeto consiste em uma açáo pedagógica, um planejamento didático produzido no contexto escolar a partir do Plano Educativo Individualizado, um documento que acompanha o processo de inclusão escolar do aluno com deficiência durante todo seu período de escolarização. Compreendemos que a inclusão das pessoas com deficiência ultrapassa o percurso escolar e, portanto, necessita de um olhar que considere todo o arco de existência da pessoa, do nascimento à vida adulta. Para tanto, organizamos o texto em três planos concomitantes, a saber: o atual contexto italiano de inclusão de pessoas com deficiência, a construção do projeto de vida durante o percurso escolar e a inclusão social através do projeto de vida na fase adulta, com destaque à inserçáo do indivíduo no mercado de trabalho. As bases teóricometodológicas contam com autores protagonistas da área da Educação Especial em diálogo com a escola e o mercado de trabalho, entre eles Andrea Canevaro e Charles Gardou. Desta escrita, destacamos a importância do trabalho multidisciplinar realizado durante o período de escolarizaçáo e garantido por lei e da compreensão de que a inclusão escolar e social da pessoa com deficiência perpassa todo o percurso da sua vida, tendo início a partir do entendimento dela como um ser humano capaz.

Palavras-chave: Educação Especial; Educação na Itália; Projeto de vida.

\footnotetext{
* Doutora em Educação pela Universidade Federal do Rio Grande do Sul, Porto Alegre, Rio Grande do Sul, Brasil.

** Pesquisador da Faculdade de Educação da Universidade de Bolonha, Bologna, Itália.

*** Pesquisadora da Faculdade de Educaçáo da Universidade de Bolonha, Bologna, Itália.
} 


\section{Special Education in the Italian context: the life project, from school to adult life}

\section{Abstract}

This work aimed to analyze the concept of life project in the Italian context. The project con-sists of a pedagogical action, an educational planning produced in school context from an Individualized Education Plan, which is a document that follows the process of inclusion of students with disabilities throughout their school years. We understand that the inclusion of people with disabilities goes beyond the school years and, thus, it needs a perspective that considers the entire arc of existence of the person with disabilities, from birth to adult life.In order to contemplate that, we have organized the work into three concomitant plans: the current Italian context of inclusion of people with disabilities; the construction of a life project through school years; and the social inclusion through life project in the adult life, with highlights to the insertion of the individual in the job market. The methodological and theoretical background is based on the works of leading authors in Special Education and its relations with the educa-tional and job market contexts, including Andrea Canevaro and Charles Gardou. From this writ-ing, we reinforce the importance of multidisciplinary work performed during the schooling peri-od, which is guaranteed by law, and the understanding that educational and social inclusion of people with disabilities pervade all their lifetimes,starting from their self-understanding as ca-pable human beings.

Keywords: Special Education; Education in Italy; Life project.

O presente texto possui como tema o processo de inclusão escolar e social das pessoas com deficiência na Itália. Entendemos que a inclusão das pessoas com deficiência ultrapassa o percurso escolar e, portanto, necessita de um olhar que compreenda todo o arco de existência da pessoa, do nascimento à vida adulta. Nessa direção, o estudo tem como objetivo analisar o conceito de "projeto de vida" ${ }^{2}$ das pessoas com deficiência no contexto italiano, compreendendo também o momento do tornar-se adulto, a fase de encontro com o mundo do trabalho. O projeto de vida consiste em uma ação pedagógica, um planejamento didático produzido no contexto escolar a partir do Plano Educativo Individualizado, um documento que acompanha o processo de inclusão escolar do aluno com deficiência durante todo seu período de escolarização.

Para alcançarmos o objetivo proposto, reconhecemos como necessário um olhar sobre a realidade italiana, contextualizando de modo breve as políticas educacionais, com especial atençáo dirigida aos processos de inclusão escolar dos alunos com deficiência. Nessa direção, organizamos o texto em três eixos: o contexto italiano, apresentando sua estrutura política, uma história de quase 40 anos de inclusão; o projeto de vida na escola; e o projeto de vida no contexto da vida adulta, no momento de inserção no mercado de trabalho. 


\section{Educação Especial no contexto italiano}

As políticas educacionais direcionadas ao campo da educação especial possuem grande destaque dentro do contexto europeu. A Itália vivenciou na década de 70 uma mudança importante em sua política educacional, com a promulgação da lei $n^{\circ} 517$ de 1977. Essa lei produziu modificações no sistema de ensino italiano, entre elas o fechamento das classes e escolas especiais, possibilitando o ingresso de todos os alunos no ensino comum. A referida normativa, já naquele momento, destacava algumas ações importantes para a efetivação de tal mudança: o professor de apoio especializado, número de alunos por turma não superior a vinte e a oferta de serviços especializados sob responsabilidade do governo e das redes locais de ensino (Estados e Municípios).

Outro marco político importante na história desse país é a lei n 104 de 1992 Itália, 1992) - "Legge-quadro per l'assistenza, l'integrazione sociale e i diritti delle persone handicappate" 3 . Ela encontra-se em vigor até os dias de hoje e orienta todo o processo e a documentação que acompanha a inclusão do aluno com deficiência na escola. Com base nela são construídos os Acordos de Programa por Região e suas respectivas Províncias ${ }^{4}$. Nesses documentos encontramos a descrição dos participantes do processo de inclusão e suas respectivas responsabilidades. É com a lei nº 104 de 1992 que pela primeira vez é levada em consideração a pessoa com deficiência, do nascimento à vida adulta, e os múltiplos aspectos que a constituem: a saúde, a inclusão escolar, a educação, a formação profissional, o trabalho, a casa e os transportes públicos, as possíveis barreiras arquitetônicas e comunicativas (PAVONE, 2007). Em conjunto com a referida lei, em 24 de fevereiro de 1994 é promulgado um Decreto Presidencial ${ }^{5}$ que define o papel do suporte técnico-especialista que os serviços de saúde devem oferecer à escola na presença de alunos com deficiência. Esse decreto e a lei n ${ }^{\circ}$ 104/1992 configuram-se como dois atos normativos que regulam até os dias de hoje as práticas cotidianas dos processos de inclusão escolar (D’ALONZO; IANES, 2007).

O percurso da pessoa com deficiência no contexto italiano inicia no momento da identificação do diagnóstico na Unidade Sanitária Local de cada município. Neste espaço, uma equipe médica produz o diagnóstico da pessoa com base na Classificação Internacional de Doenças e Problemas Relacionados à Saúde - CID 10, emitindo um documento nomeado "Certificazione dell'integrazione scolatisca" ${ }^{\text {" }}$. Em paralelo a essa documentação, é produzido um diagnóstico funcional com base na Classificação Internacional de Funcionalidades - CIF, produzido pela Organização Mundial da Saúde (OMS, 2001). De acordo com o estudioso Andrea Canevaro (2007) a lógica da CIF visa desconstruir a situação de deficiência, evitando limitar o diagnóstico na ótica de uma única categoria. Assim, o diagnóstico funcional visa atentar para as capacidades, potencialidades e dificuldades da pessoa em situação de deficiência.

A CIF [...] apresenta uma forma de diagnosticar muito diferente daquela conhecida como a função do diagnóstico, ou seja, de classificar, de colocar em uma certa categoria quem apresenta dificuldades de natureza constante ou transitória. O nosso olhar é mais ligado à deficiência irreversível - logo ao déficit - e necessitamos de um diagnóstico que seja funcional. Tudo isso é acompanha- 
do por uma reflexão e por práticas que permitem a valorização das potencialidades dos sujeitos nas suas diferenças. Em síntese: reconhecer a identidade no pertencimento (CANEVARO, 2006, p.122, grifos do original).

$\mathrm{Na}$ continuidade do percurso, a equipe médica responsável pelo diagnóstico tem até 45 dias para emissão dessa documentação. Tendo em mãos esses documentos, a garantia de uma vaga na escola e de acesso a um apoio especializado é salvaguardada à pessoa com deficiência. Unem-se a esse percurso dois outros importantes documentos. O primeiro deles é o Perfil Dinâmico Funcional - PDF, produzido com base no diagnóstico funcional e escrito pelo grupo operativo, ou também chamado "equip", constituído pelos professores, equipe de saúde e família da pessoa com deficiência. A ideia é que todos aqueles envolvidos no processo de inclusáo da criança, desde seu momento de ingresso na escola, trabalhem de forma coletiva e em rede. O referido documento deve ser atualizado obrigatoriamente na passagem de cada etapa de ensino e compreende dois encontros anuais desse grupo. O segundo documento a ser destacado é o Plano Educativo Individualizado - PEI, escrito também pelo grupo operativo, com especial participação do professor curricular e do professor de apoio especializado. Esse plano é desenvolvido nos primeiros dois meses de escola e é atualizado anualmente. A família participa de todo esse percurso e da produção dessa documentação, ficando com uma cópia para acompanhamento.

Nessa direção, encontramos no contexto italiano um apoio especializado descentralizado, em forma de rede, cujos fios não se restringem ao professor de apoio, mas a todos aqueles presentes no contexto escolar e aos demais envolvidos no percurso de vida da pessoa com deficiência. O processo de inclusão escolar se materializa na figura de profissionais envolvidos no percurso da pessoa com deficiência, não possuindo um espaço específico de trabalho individual com o aluno, mas sim prestando apoio ao coletivo de alunos. A engrenagem que possibilita o funcionamento dessa rede de profissionais intersetoriais conta com um contexto político estruturado que possibilita e sustenta os processos de inclusão do país. Nesse caso, os Acordos de Programa ${ }^{7}$ por Região e suas respectivas Províncias possuem importante papel, pois é neles que encontramos a descrição da documentação a ser produzida, as figuras profissionais envolvidas e suas respectivas responsabilidades.

$\mathrm{Na}$ continuidade entraremos no mundo da escola, com o objetivo de apresentar de que forma o conceito de projeto de vida está presente nesse percurso escolar.

\section{projeto de vida e a escola}

No âmbito educacional, nos parece inapropriada a perspectiva de impedir ou limitar à uma pessoa, as suas perspectivas e os seus projetos para o futuro. É comum encontrarmos tal situaçáo quando o aluno possui alguma deficiência, pois os limites podem obscurecer a visão de quaisquer possibilidades para o futuro. Neste caso, a pesquisa contínua das realizaçôes e conquistas da pessoa adquire um significado substancial e parece necessário que o contexto escolar permita ao aluno com deficiência definir-se também autonomamente, ensinando-o a compreender suas próprias potencialidades e limites, suas próprias aspiraçôes e expectativas e, assim, os seus próprios sonhos. 
Os diversos contextos podem acolher e alimentar as aspiraçóes e as perspectivas futuras da pessoa com deficiência, se aquele que se encontra no contexto de interação com essa pessoa deseja pensá-la e imaginá-la no futuro, hipotetizando possíveis objetivos. Trata-se de acompanhar a pessoa com deficiência a partir de açóes de orientação e de reorientação, sem renunciar às imprevisíveis mudanças de rota, adaptaçóes e ajustes no itinerário, que podem oferecer novos significados e futuras oportunidades. Desse modo, a ação de orientação se delineia, precisamente, como processo que se realiza gradualmente, a partir de escolhas e imprevistos ligados entre si. Cabe aos professores agir com o intuito de compreender os desejos e as atitudes de seus alunos, a partir de uma ação de acompanhamento que incentive, estimule-os também a tomar decisóes conscientes e autônomas. Aquele, porém, chamado por diferentes papéis e nomeaçóes, a sustentar o crescimento da pessoa com deficiência, deveria evitar assumir uma postura de manipulação, se distanciando da tentação de estabelecer a priori percursos e escolhas com o objetivo de proteger a pessoa com deficiência, vindo a intervir com um comportamento protetor na relação com ela.

O objetivo prioritário dos professores poderia ser aquele de permitir ao aluno com deficiência, de acordo com as suas possibilidades, aventurar-se autonomamente no mundo, mas para atingir esse objetivo, cabe a cada professor fazer com que esse aluno experimente o impulso emotivo que surge quando se aprende com autonomia, quando, para realizar uma tarefa, é necessário recuperar toda sua própria eficiência e determinação.

No contexto escolar, a ação de orientação não é reduzida a um instrumento para administrar a passagem de um ano escolar para outro, ou até mesmo para a formação profissional, mas sim assume um valor permanente na vida da pessoa. Por isso, não pode limitar-se a açóes fragmentadas presentes em cada momento do percurso escolar de forma individual, devendo entrar em uma perspectiva de projeção, de planejamento que favoreça, de forma gradual, desde a escola infantil, a tomada de consciência de si.

[...] o acesso ao mundo dos adultos e, em particular a inserção no mercado de trabalho de uma pessoa com deficiência, não se constrói em modo histórico e a uma certa idade cronológica, mas consiste no resultado de um percurso educativo-afetivo e de experiência que toma o começo precocemente, próprio de um imaginário e de um projeto que se realiza passo a passo, dia após dia, com a condiçáo que se tenha compreendido em qual direçáo andar e quais passos cumprir/realizar (MONTOBBIO, 2000, p.26).

Quais são as tarefas atribuídas à escola em relação ao conceito de orientação? Damos destaque para três: a elaboração de aprendizagens disciplinares com o objetivo de reforçar e/ou adquirir competências e informaçôes úteis - ao aluno e ao professor - para a orientação; a produção de experiência - estágio, alternância escola e trabalho - para os alunos que estão no espaço profissional ligado ao nível escolar que frequentam, para monitorar as competências adquiridas e seus interesses; a ativação de um acompanhamento educativo e formativo sobretudo nas passagens, entradas e saídas, nos diversos âmbitos formativos e de trabalho: a orientação como acompanhamento na 
reorientação constante. Para serem realizadas, as açōes elencadas requerem abordagem flexível na passagem de um tipo de instituiçáo para outra, a partir de mudanças que não excluam saídas e/ou entradas motivadas exclusivamente de uma exigência de planejamento.

Nessa direção, faz-se necessária uma perspectiva educativa e formativa que incentive ações abertas a múltiplas passagens e estruturações do projeto de vida para os alunos com deficiência. É imprescindível que os professores programem, acompanhem continuamente e solicitem autoavaliaçóes que sustentem e promovam as escolhas, favorecendo contemporaneamente a expressão das potencialidades dos alunos. A escola precisaria construir, de um lado, uma aprendizagem significativa, autêntica, e por outro lado, reforçar aqueles componentes psicológicos que sustentam o conhecimento e a percepção de si, o autorreconhecimento de interesses, coerentes com as próprias potencialidades e limites. Para poder gerenciar ambas perspectivas, é indispensável que a aprendizagem se estruture sobre a lógica de cooperação e de coconstrução, pois é a partir da relação com o outro que se aprende e que se conhece.

\footnotetext{
É limitador pensar em uma prática voltada a sustentar de modo específico e exclusivo as açóes para e com o aluno com deficiência, enquanto que é mais interessante pensar em uma prática direcionada a todos, considerando as especificidades de cada um. Uma prática pedagógica [...] capaz de estimular açôes que garantem a aprendizagem que nasce, se desenvolve, se fixa como co-construção e não como transferência de elementos a serem implementados ou somados. (DAINESE, 2012, p.29).
}

Parece-nos que o objetivo da escola é o de promover uma consciente ação educativa e prática pedagógica voltadas a favorecer a definição de personalidade que podem ser delineadas sobre pressupostos de autodeterminaçáo, que surgem não na solidão, mas através de uma relação autêntica com seus pares.

A presença de um aluno com deficiência em uma turma produz efeitos inclusivos que não correspondem a uma oportunidade exclusivamente para o aluno com deficiência, mas que oferece vantagens e oportunidades para todos. A combinação de aprendizagem e socializaçáo nos leva, inevitavelmente, a um dos "nós" centrais da ação inclusiva na escola, a qual depende também do tempo efetivo que o aluno com deficiência permanece em turma com os demais colegas. Negar, ou somente limitar a presença do aluno com deficiência na turma, significa negar uma oportunidade de crescimento educativo direcionada a estimular uma valorização das diferenças individuais.

A atençáo dos professores deve ser colocada sobre o grupo de alunos, sobre a turma, e a proposta de aprendizagem poderia ser construída sobre níveis personalizados de dificuldade, para evitar oferecer exclusivamente aquilo que está disponível, vindo a simplificar excessivamente tarefas e materiais, inibindo a ideia de uma aprendizagem significativa baseada nos desejos de quem aprende de colocar-se em jogo provando o sentido de novas conquistas, mesmo que seja trabalhoso. Vygotsky sugere colocar o desafio - aquele referente à aprendizagem - naquilo que ele nomeou de zona 
do desenvolvimento proximal, na qual é possível aprender enfrentando obstáculos cognitivos superáveis, sem muitas facilitaçôes ou frustrantes barreiras.

A aprendizagem é, para Vygotsky, um processo construtivo, que precisa de uma arquitetura sustentada por mediadores que permitem o lançamento de desafios cognitivos personalizados. É possível reconhecer nos mediadores características muito úteis no âmbito educativo e formativo, características que garantem uma aprendizagem apropriada. Entre elas, destacamos algumas: os mediadores devem colocar-se dentro de um projeto que favoreça a participação de todos, promovendo interaçôes autênticas entre todos aqueles envolvidos na ação de aprendizagem; os mediadores, mesmo quando o funcionamento da pessoa apresente limitaçóes e obstáculos, devem estimular o crescimento, a mudança e não uma aparente estagnação. Assim, os mediadores, na prática pedagógica, representam os facilitadores e não a "prótese". Não podem e não devem normalizar o ato de aprender, devem simplesmente favorecer uma aprendizagem possível.

Canevaro (2008) reconduz a reflexão sobre a figura do mediador à importância da programação, do planejamento, reconhecendo no projeto as características do mediador:

Construir um projeto, saber fazer um projeto é ser um mediador. Possibilita não fazer referência unicamente à própria pessoa do profissional, mas a um desenho, a uma estruturaçáo, na qual com uma progressáo colocamos tanto o profissional, quanto os outros. [...] Os mediadores tornam-se interessantes porque fazem nascer a possibilidade de criar espaços, articulaçóes flexíveis entre os diversos elementos que compóe a realidade, e superar a compreensão que uma catástrofe pode ter criado, impedindo distinguir os diferentes elementos que compóe a própria realidade. (p.49).

$\mathrm{O}$ projeto de vida permite agir com consciência em um contexto alargado e não circunscrito a poucos, a dois: o aluno com deficiência e um único profissional da escola (ele e "seu" professor especializado, ele e "seu" educador...). As relaçóes restritas somente a poucos adultos prejudicam a construção de um "eu", de uma identidade que se define em um mundo amplo e que se nutre de curiosidade e de coragem intencional. A curiosidade poderia ser sentida por todos como desejo pessoal de explorar aquilo que circunda a pessoa e de explorar-se para conhecer-se na sua própria interioridade. Mas a curiosidade, o incentivo à investigação autônoma, geralmente não é um pressuposto oferecidos à pessoa com deficiência. É mais fácil silenciá-los, prendendo a sua curiosidade, a sua liberdade de ação. Esses acontecimentos não somente impedem a experiência escolar de ser significativa, mas inibem as funçóes superiores que permanecem adormecidas, até não alcançarem o plano da realizaçáo consciente para a qual o sujeito se convence de não poder, de náo saber. $\mathrm{E}$ o tempo permanece vinculado a uma constante privação de novidade, impedindo um olhar sobre qualquer coisa possível. Edgar Morin escreve:

A educação deve favorecer a atitude global da mente a propor e a resolver os problemas e correlativamente deve estimular o pleno uso da inteligência global. Esse pleno uso exige o livre exercício 
da habilidade mais difundida e mais viva da infância e da adolescência, a curiosidade, a qual, muitas vezes, o professor apaga e que, ao contrário de estimular ou acordar, adormece (MORIN, 2000, p.16).

As palavras do autor não podem ser úteis somente quando fazemos referência a alguns alunos, com exceção daqueles com deficiência, mas, ao invés disso, devem dizer respeito a todos, porque é sobre a curiosidade que se deve estruturar o projeto de vida de cada um. A todos deveria ser reconhecido o direito de conseguir um espaço no mundo. Seguindo a linha desse direito, passamos para o terceiro plano de análise do texto, colocando em foco o projeto de vida naquele momento em que a pessoa com deficiência se torna adulta e, consequentemente, do encontro com o mundo do trabalho.

\title{
Projeto de vida e o mundo do trabalho: instrumento, percurso e oportunidade
}

Mesmo para um neófito que ouve pela primeira vez a expressão "projeto de vida" fica claro como no pensamento que a sustenta está presente uma dimensão temporal. A imagem que poderia nascer no seu pensamento é aquela da linha do tempo: existe um presente precedido de um passado e seguido por um futuro. Pedagogicamente, o futuro representa a parte daquela linha do tempo, na qual se desenvolve um imaginário que "[...] deveria ser pensado como o tempo do cuidado da complexidade infinita do real humano, em todos os campos da sociedade (GARDOU, 2006, p.50)". Se isso é válido para cada pessoa, é também para quem possui alguma deficiência: possuir um papel a desenvolver é aquilo que a sociedade espera de nós. Referindo-se às pessoas com deficiência, Gardou (2006) destaca quatro condiçôes indispensáveis para desenvolver plenamente o próprio papel na comunidade humana, condiçôes que acompanham todo o arco da vida:

\begin{abstract}
[...] reconhecimento - não existe um sujeito sem um outro que o reconheça como tal na sua diferença; autonomia - não existe um sujeito sem um outro que acompanhe a sua conquista pela autonomia; direito - não existe um sujeito sem um outro que reconheça os seus direitos e a sua dignidade; o dizer e o agir - náo existe uma pessoa com deficiência que possa constituir-se como sujeito sem uma sociedade que traduza em atos as suas intençóes democráticas e de inclusáo (p.39).
\end{abstract}

Trata-se de quatro condiçóes que deveriam, necessariamente, acompanhar o projeto de vida de cada um. Como consequência, poderiam constituir quatro pilares imprescindíveis na construção de qualquer outro projeto educativo que poderia ser inserido em um percurso de projeto de vida. Certamente, essa fase não pode ser desconectada daquelas que a precedem. $\mathrm{Na}$ verdade, o processo de reconhecimento, de desenvolvimento da autonomia, do exercício dos próprios direitos e a possibilidade de colocar em ação aquilo que foi aprendido inicia-se muito antes da pessoa tornar-se adulta. No momento em que se assume a construçáo de um projeto inicia-se um verdadeiro e próprio processo de reconhecimento que, como lembra Canevaro (2004a), "[...] deve entrar em um contexto cultural, mental, pessoal e por isso não deve ser 
unicamente aceita assim como chega, mas deve ser reformulada, reorganizada, completada; deve dar lugar a questionamentos, dúvidas, reorganizaçóes" (p.229).

Quando se fala sobre projeto não podemos partir de um raciocínio que procede de processos que partem da responsabilidade do cuidado do outro até expressarem-se em métodos e formas específicas, personalizados para a vida adulta em diante, quando se tem a possibilidade de acessar o trabalho, as intervençóes que pertencerão, principalmente, a planejamentos peculiares úteis à inserção e à manutenção do papel trabalhador. Enfim, para que um projeto possa alcançar o maior grau de eficiência possível, é necessário que seja adaptável à evolução das suas próprias necessidades.

É possível separar três grandes aspectos da vida adulta que no mundo do trabalho, em determinadas circunstâncias, podem encontrar espaço para desenvolver-se. Primeiramente, as pessoas inseridas no mundo do trabalho podem ter a oportunidade de mostrar suas capacidades e competências, aumentando sua própria autoestima e autorrealização. Por outro lado, esse é um lugar no qual se pode experimentar igualdade de oportunidades e o recebimento de um salário. O mundo do trabalho, na nossa sociedade contemporânea ocidental, dita também o desenho dentro do qual se inserem muitos dos aspectos da identidade adulta: às vezes nascem e se constituem dentro da mesma identidade profissional, outras vezes, nas relaçóes interpessoais que se instauram, ou até mesmo nas competências que se desenvolve. Se por trabalho entendemos uma tensão em direção a um objetivo e, ao mesmo tempo, uma atividade tradicionalmente ambígua, na qual está presente tanto o aspecto de restrição, como o de autorrealização, na sua maioria, o trabalho pode ser um elemento principal da vida adulta, momento cuja responsabilidade e autorrealização alcançam seu pleno potencial de desenvolvimento.

No trabalho estão sempre presentes, na verdade, em modo mais ou menos latente, dois aspectos: de um lado a tensão em direção a uma autoapreciação ligada à consciência de ter construído algo, de ter gerado um resultado útil. Por outro lado, há o sentimento inevitável de limitação da própria liberdade e de restrição (BRUSCAGLIONI, 2005).

Em consonância com D'Alonzo (2009), acreditamos que o trabalho seja fundamental do ponto de vista econômico, porque oferece a base suficiente para suportar os custos de uma vida sempre mais complexa; do ponto de vista do crescimento da identidade, pois contribui para formar na pessoa a consciência do próprio "eu" e de sua própria habilidade; do ponto de vista social, enquanto permite ao sujeito viver no interior de um contexto humano e cultural normal, e por contribuir ao bem-estar da sociedade. Daí a importância de inserir esses aspectos em um projeto de vida amplo que compreenda a pessoa na sua totalidade.

Ao abordar o tema sobre as pessoas adultas com deficiência, é importante recordar como "[...] a deficiência em si mesma não constrói nem um destino, nem uma identidade. Antes de ser deficiente, a pessoa simplesmente existe (GARDOU, 2006, p.49)". Muitas vezes, não é possível "dar por sabida" essa simples afirmação. Frequentemente, ocorre da pessoa com deficiência desaparecer atrás de sua deficiência ou de seu déficit, perdendo ou sendo diretamente privada de sua real identidade social. 
Nessa direção, a construção de uma identidade adulta tem necessidade de ser inserida em uma perspectiva de futuro.

\begin{abstract}
Para ser eficiente, a educaçáo deve ser orientada sobre duas diretivas: uma via leva a pessoa com deficiência a tornar-se e a conceber-se como "cidadáo" pleno na sociedade; a outra, exige que a pessoa com deficiência adquira habilidades suficientes, se possui potencial, para tornar-se um "trabalhador", ou seja, uma pessoa que produz e opera no mundo econômico-produtivo da atualidade (D’ALONZO, 2009, p.90).
\end{abstract}

Por outro lado, nos parece interessante recordar que ao considerar a pessoa com deficiência enquanto pessoa, sinalizamos "[...] o começo de um processo de superação da rígida distinção normalidade/diferença, reconhecendo que as pessoas com deficiência, enquanto 'pessoas', possuem os mesmos direitos de todos os seres humanos e que esses direitos são reconhecidos e garantidos pela sociedade" (LEPRI, 2011, p.71).

Ao refletirmos sobre o projeto de vida e o mundo do trabalho, é importante lembrar que são ao menos três os níveis sobre os quais é preciso intervir: o nível pessoal, aquele do local de trabalho e o do contexto sociocultural. O projeto de vida é chamado a relacionar-se com todos esses três níveis. De um lado, não pode prescindir do contexto social e cultural, como também das características e das competências das pessoas com deficiência. Por outro lado, é necessário que seja estritamente ligado à organização de trabalho na qual a pessoa está inserida. O contexto do trabalho não pode ser algo do externo, ou seja, independente do sujeito, mas sim, uma rede de relaçóes, normas, narrativas, nas quais os aprendizados são o produto da interação recíproca entre a pessoa, o trabalhador com deficiência e o próprio contexto que coevolui e também aprende, modificando-se, adaptando-se, com vantagens gerais que alcancem a todos os trabalhadores (ZANELLI, 1986).

Parece-nos interessante destacar como o mercado de trabalho necessita de centros de informação/formação com o intuito de possibilitar, por exemplo, percursos formativos para tutores de empresa - figura chave no apoio aos processos inclusivos - na realização e implementação de instrumentos para o planejamento dos profissionais e os próprios destinatários. Para uma boa inclusão no mercado de trabalho, nos parece indispensável uma colaboração com e entre os serviços sociossanitários, o Estado e o Municipio e principalmente a colaboração, que precisa tornar-se uma aliança, a ser feita com a família e com o contexto de trabalho. As condiçóes facilitadoras que caracterizam um contexto de trabalho idôneo são aquelas que fazem com que o espaço seja caracterizado pelo "aprender com", segundo expectativas de papel, entre colegas, e não para deixar contente o trabalhador de referência, reproduzindo, de tal modo, cuidados infantis ou assistenciais. Construir um projeto de vida que contemple a rede, significa valorizar os componentes de participação, de colaboração, de diálogo transversal com as instituiçôes e instâncias governamentais, e com um percurso que se torna, dessa forma, acessível a todos.

Concordamos com Canevaro (2004b) quando afirma que [...] o projeto de vida é um processo que valoriza, permitindo e favorecendo a compreensão daquilo 
que está acontecendo, por uma valorização contínua e real. É sobre isso que se deve fundar uma organização de rede. (p.518)

O desenvolvimento de redes entre os serviços e as empresas daquele território pode ajudar a individualizar aspectos e situações que contribuam na evolução do âmbito do qual nos ocupamos. Nessa direção, é necessário supervisionar os mecanismos relacionais com o intuito de nunca perder o objetivo daquilo que será programado, planejado.

Poderia-se reformular tudo isso, dizendo que na cooperação é importante náo haver uma total autorreferência, mas compreender qual é o elemento que transcende o individual e constrói a cooperaçáo em si. Por isso a necessidade do projeto de vida de uma pessoa com deficiência ter na cooperação um elemento forte, para que as exigências do individual tenham a possibilidade de integrar-se no elemento que transcende o individual. (CANEVARO, 2004b, p.518).

O risco sempre presente é de que, realizando um percurso particular, se consolide as distâncias da perspectiva geral e se esqueça que o projeto de vida necessita permitir uma valorização da identidade em seu mais amplo pertencimento social possível.

\section{Considerações}

Nos últimos anos, a comunidade escolar do contexto italiano vivenciou não somente a presença dos alunos com deficiência na escola, como também a construção de um diálogo com outros colaboradores/figuras externas ao contexto escolar, como médicos, psiquiatras, profissionais do serviço social do município, construindo um trabalho multidisciplinar, vindo a produzir uma série de percursos de experiências no campo da inclusáo escolar.

Por outro lado, para promover a inclusão social, acreditamos que seja indispensável a produção de percursos que coloquem o trabalho como uma capability, a qual todos têm direito e que a comunidade inteira deve garantir, através da assunção de uma responsabilidade difusa e diferenciada (SEN, 2005). Em outras palavras, todas as pessoas podem ser produtivas se lhes são ofertadas oportunidades e competências para isso. Portanto, deve-se pontuar as lacunas e superar os eventuais obstáculos que não permitem o desenvolvimento dessa capability ${ }^{8}$.

Por fim, pensamos serem necessários percursos que antevejam uma abordagem participativa que valorize as experiências dos profissionais envolvidos, olhando também para o campo acadêmico, considerando as práticas presentes há mais de trinta anos no contexto italiano, dando espaço aos processos de formação dos profissionais, tanto dos professores de apoio, como dos tutores presentes na inserção ao mercado de trabalho. Prevendo ainda espaços de comunicação, que possibilitem o trabalho multidisciplinar realizado durante o período de escolarização. Tendo assim a compreensão de que a inclusão escolar e social da pessoa com deficiência perpassa todo o percurso da sua vida, tendo início a partir do entendimento dela como um ser humano capaz. 


\section{Referências}

BRUSCAGLIONI, M. Per una formazione vitalizzante. FrancoAngeli: Milano, 2005.

CANEVARO, A. Se nasce un bambino o una bambina disabile. In: Quaderni acp, n. 11, p. 229 - 234. 2004 a.

. Interazione e progetto di vita, In: Disabilità, Integrazione e pedagogia speciale, numero monografico 3, p. 517 - 526. 2004 b.

. Le logiche del confine e del sentiero: Una pedagogia dell'inclusione (per tutti, disabili inclusi). Trento: Erickson, 2006.

L'integrazione scolastica degli alunni con disabilità: trent'anni di inclusione nella scuola italiana. Trento: Erickson, 2007.

Pietre che affiorano. Trento: Erickson, 2008.

DAINESE, R. Pensare la didattica come pratica inclusiva. Padova: CLEUP, 2012.

D'ALONZO, L. Il protagonismo del figlio disabile adulto: lavoro, università. In: PAVONE, M. (a cura di) Famiglia e progetto di vita: Crescere un figlio disabile dalla nascita alla vita adulta. Erickson: Trento, 2009.

GARDOU, C. Diversità, vulnerabilità e handicap: Per una nuova cultura della disabilità. Erickson: Trento, 2006.

D'ALONZO L.; IANES, D. L'integrazione scolastica dal 1977 al 2007: i primi risultati di una ricerca attraverso lo sguardi delle famiglie. In: CANEVARO, A. (a cura di). L'integrazione scolastica degli alunni con disabilità: trent'anni di inclusione nella scuola italiana. Trento : Erickson, 2007, p.185 - 202.

ITÁLIA. Legge 4 agosto $\mathbf{1 9 7 7}$, n. 517. Norme sulla valutazione degli alunni e sull'abolizione degli esami di riparazione nonche' altre norme di modifica dell'ordinamento scolastico. Camera dei deputati ed il Senato della Repubblica, 1977.

ITÁLIA. Legge 5 febbraio 1992, n.104. Legge-quadro per l'assistenza, l'integrazione sociale e i diritti delle persone handicappate.

Decreto Presidente della Repubblica 24 febbraio 1994. Atto di indirizzo e coordinamento relativo ai compiti delle unità sanitarie locali in materia di alunni portatori di handicap.

. Provincia di Bologna. Accordo di programma provinciale per l'integrazione scolastica e formativa dei bambini e alunni disabili, 2008-2013 (Legge 104/1992). 2008.

LEPRI, C. Viaggiatori inattesi: Appunti sull'integrazione sociale delle persone disabili. Franco-Angeli: Milano, 2011.

MONTOBBIO E.; LEPRI, C. Chi sarei se potessi essere. Pisa: Edizioni del Cerro, 2000.

MORIN, E. La testa ben fatta: Riforma dell'insegnamento e riforma del pensiero. Milano: Raffaello Cortina, 2000 .

OMS, Organizzazione Mondiale della Sanità. Classificazione Internazionale del Funzionamento, della Disabilità e della Salute. Trento: Erickson, 2001.

PAVONE, M. La via italiana all'integrazione scolastica degli allievi disabili. Dati quantitativi e qualitativi. In: CANEVARO, A. (a cura di). L'integrazione scolastica degli alunni con disabilità: trent'anni di inclusione nella scuola italiana. Trento : Erickson, 2007. p.159 - 183.

SEN, A. Justice and human disabilities. Laurea Honoris Causa dell'Università di Pavia, 2005.

VYGOTSKY, L. S. Linguagem, desenvolvimento e aprendizagem. São Paulo: Ícone, 2006.

ZANELLI, P. Uno “sfondo” per integrare. Cappelli: Bologna, 1986.

\section{Notas}

${ }^{1} \mathrm{O}$ presente artigo é fruto do trabalho compartilhado entre os três autores do texto. Porém, a pedido dos dois autores italianos presentes nesta publicação, para que a mesma também seja válida na Itália, atribuímos a parte escrita no item "O projeto de vida e a escola" a Roberto Dainese e a parte intitulada "Projeto de vida e o mundo do trabalho: instrumento, percurso e oportunidade" a Valeria Friso.

${ }^{2} \mathrm{Na}$ língua de seu contexto de origem: progetto di vita. 
${ }^{3}$ Lei-quadro para a assistência, integração social e os direitos das pessoas handicappate.

${ }^{4}$ A Itália é uma república parlamentar unitária cuja capital é a cidade de Roma. Como primeira subdivisão o país possui 20 regióes, cada uma com suas respectivas capitais. Essas 20 regióes são compostas por 109 províncias.

${ }_{5}^{5}$ Decreto Presidente della Repubblica 24 febbraio 1994. Atto di indirizzo e coordinamento relativo ai compiti delle unità sanitarie locali in materia di alunni portatori di handicap.

${ }^{6}$ Certificado de inclusão escolar.

${ }^{7} \mathrm{O}$ Acordo tem como objetivo promover o bem-estar e o 'sucesso formativo' das crianças e dos alunos com deficiência, com atenção ao pleno desenvolvimento das suas capacidades, do valor de sua presença como recurso didático-formativo também para a turma, à continuidade educativa e ao projeto de vida na sua totalidade." (Accordo di Programma, 2008, p.10).

${ }^{8}$ Ver Friso V. (2013) Inclusione sociale, lavoro e capability, in Formazione \& Insegnamento, n. 1, pp. 91 - 102.

\section{Correspondência}

Melina Chassot Benincasa Meirelles - Universidade Federal do Rio Grande do Sul, Faculdade de Educação, Núcleo de Estudos em Políticas de Inclusão Escolar. Av. Paulo Gama s/n, Prédio 12201, $9^{\circ}$ andar sala 910, Farroupilha. CEP: 90046900 - Porto Alegre, Rio Grande do Sul - Brasil.

E-mail: melinabenincasa@gmail.com - roberto.dainese@unibo.it - valeria.friso@unibo.it

Recebido em 13 de agosto de 2015

Aprovado em 31 de agosto de 2016 
